\title{
Reconstruction of Non-linear Path Analysis Accompanied by Measurement Models on Food Security Models in Indonesia Post- Covid19 Pandemic based on Big Data
}

\author{
SOLIMUN, ADJI ACHMAD RINALDO FERNANDES, NURJANNAH, INDAH YANTI, \\ LUTHFATUL AMALIANA, EVA FADILAH RAMADHANI, \\ FATHIYATUL LAILI NUR RASYIDAH \\ Department of Statistic \\ Brawijaya University
}

St. Veteran, Lowokwaru, Malang, East Java

INDONESIA

\begin{abstract}
This study aims to map and model the determinants of food security. Mapping is done by cluster and biplot analysis, while modeling is done by non-linear path analysis. This research is mix-method research that combines quantitative and qualitative research. In the qualitative method, this study applies a qualitative Discourse Network Analysis (DNA) approach. Sources of DNA data come from various information in cyberspace (mass media, journals, articles, etc.) that are in accordance with the research context. In DNA data processing, statements, actors, concepts/issues, sentiments, along with the origin of the organization will be generated. As for the quantitative method, this study uses descriptive statistical analysis, biplot, cluster, and non-linear path analysis (square and cubic). The coefficient of determination for both quadratic and cubic path analysis is 0.88 , which means that the influence of the independent variable simultaneously on the $\mathrm{Y}$ variable is 0.88 , which is very strong. Thus, the model formed is quite good because the predictor variable is able to explain food security by $88 \%$ while the rest is explained by other factors outside the model. The originality of this research is the reconstruction of non-linear path analysis which is more flexible (no need for assumptions of normality and homogeneity) and is equipped with a measurement model.
\end{abstract}

Key-Words: - Discourse Network Analysis, Food Security, Cluster, Biplot, Non-Linear Path, Flexible Model.

Received: May 30, 2021. Revised: November 1, 2021. Accepted: November 14, 2021. Published: December 1, 2021.

\section{Introduction}

Food security is very important for all countries, which is related to the availability of food to meet the needs of the community. The stakeholder who plays an important role in achieving food security in Indonesia is Perum BULOG. Maintained food security can enable a country to survive in the face of a food crisis in the event of a natural or non-natural disaster. One of the non-natural disasters that are currently happening is the Covid-19 pandemic. This pandemic has hit almost several countries since the end of 2019 and entered Indonesia in March 2020. The government is trying to overcome the pandemic by implementing Large-Scale Social Restrictions (PSBB). However, this has slowed down the business and economic activities of various sectors in
Indonesia. One sector that is quite threatened is the agricultural sector.

From these problems, this study aims to map and model the determinants of food security. Mapping is done by cluster and biplot analysis, while modeling is done by path analysis. Path analysis can accommodate direct and indirect effects. But on the other hand, path analysis is inflexible because it must meet several assumptions, one of which is the assumption of linearity. In the application of path analysis, it is quite difficult to fulfill the assumption of linearity. The relationship between variables can be non-linear, namely cubic, quadratic, and others. In addition, path analysis also requires the fulfillment of the assumptions of normality of error and homogeneity of variance of error. Path analysis also has drawbacks. namely, the measurement model that must be carried out 
outside the structural model, and the relationship between variables is not reciprocal. Based on this description, the urgency of this research is the reconstruction of non-linear path analysis which is more flexible (no need for assumptions of normality and homogeneity) and is equipped with a measurement model.

Research on food security has been carried out by Saediman et al. [1] which resulted that the home food gardening program made a positive contribution to household food security and this program is an important strategy to address food insecurity and nutrition deficiency of low-income households. Research on food security was also conducted by [2]. The results showed that there was a long-term relationship between the determinants of wheat consumption in Egypt. It is recommended that the Egyptian government should focus on exploring ways including bio-saline farming to increase domestic wheat production to reduce wheat imports, save valuable foreign exchange, and address some of Egypt's food security challenges.

Research conducted by Ly et al. [3] regarding food security gives results showing that there is a positive impact of international trade on food security in the three aspects of food availability, stability, and access in each country. In addition, other factors such as agricultural productivity, share of agricultural land to total land area, percentage of farmers in the population, and inflation also affect the food security of Southeast Asian countries in several aspects. Furthermore, [4][5] also conducted research on food security.

\section{Literature Review}

\subsection{Discourse Network Analysis}

In the qualitative method, this study applies a qualitative Discourse Network Analysis (DNA) approach which aims to identify variables that can affect Food Security in Indonesia Post-Covid-19 Pandemic. Sources of DNA data come from various information in cyberspace (mass media, journals, articles, etc.) that are in accordance with the research context. Based on the search results in cyberspace, obtained about 60 relevant content discussing the reconstruction of non-linear path analysis accompanied by measurement models on food security models in Indonesia after the Covid19 pandemic based on big data related to this research. The content is then used for DNA analysis by processing it on the Discourse Network Analyzer software. In DNA data processing, statements, actors, concepts/issues, sentiments, along with the origin of the organization will be generated.

The interrelationships between the sections (groups) of these issues can be used to construct major propositions. Thus, the major proposition can be formulated as follows.

1) Input issues affect process issues

2) Process issues affect output issues

3) Output issues affect food security in Indonesia after the Covid-19 pandemic

According to [6], a theory or model can be presented through one or a combination of the following 3 forms:

a) Verbal formulation. In this form, it means that the theory or model is presented in a series of descriptions which are theoretical statements.

b) Mathematical formula

c) Curves, graphs, or displays

\subsection{Cluster Analysis}

Cluster analysis is a statistical technique that is useful for grouping objects or variables into certain groups. According to [7], each object or variable that is formed has adjacent properties and characteristics. In practice, cluster analysis is used to segment a number of consumers (respondents) into several groups (clusters) based on the similarity of a number of defined attributes. According to [8] cluster analysis is a method in multiple variable analysis that aims to classify units of observation into groups based on variables.

\subsection{Biplot Analysis}

Biplot analysis was introduced by Gabriel in 1971 . Biplot a Biplot analysis was introduced by Gabriel in 1971. Biplot analysis is a form of multiple variable analysis (APG) that can provide a graphic description of the proximity between objects, the diversity or correlation of variables, and the relationship between objects and variables [9]. A biplot is an attempt to describe the data in the summary table in a two-dimensional graph. The information provided by the biplot includes objects and variables in one image. Biplot analysis is descriptive with two dimensions that can visually present a group of objects and variables in one graph. The graph generated from this biplot is a graph in the form of a flat plane. With a presentation like this, the characteristics of the variable and object of observation as well as the relative position 
between the object of observation and the variable can be analyzed [8][10]. Biplot analysis aims to describe the rows (objects) and columns (variables) that exist in the data matrix together in a lowdimensional graph (usually two or three). This description includes the diversity and correlation between variables, as well as the proximity between objects which will later be able to identify the grouping of objects. Biplot analysis is able to directly display the defining variable or the most dominant variable from a group of objects formed in the results of the biplot analysis display [11]. Biplot analysis aims to describe the rows (objects) and columns (variables) that exist in the data matrix together in a low-dimensional graph (usually two or three). This description includes the diversity and correlation between variables, as well as the proximity between objects which will later be able to identify the grouping of objects. Biplot analysis is able to directly display the defining variable or the most dominant variable from a group of objects formed in the results of the biplot analysis display [11]. Biplot analysis aims to describe the rows (objects) and columns (variables) that exist in the data matrix together in a low-dimensional graph (usually two or three). This description includes the diversity and correlation between variables, as well as the proximity between objects which will later be able to identify the grouping of objects. Biplot analysis is able to directly display the defining variable or the most dominant variable from a group of objects formed in the results of the biplot analysis display form of multiple variable analysis (APG) that can provide a graphic description of the proximity between objects, the diversity or correlation of variables, and the relationship between objects and variables [6][9]. A biplot is an attempt to describe the data in the summary table in a two-dimensional graph. The information provided by the biplot includes objects and variables in one image [10][11]. Biplot analysis is descriptive with two dimensions that can visually present a group of objects and variables in one graph. The graph generated from this biplot is a graph in the form of a flat plane [12][13]. With a presentation like this, the characteristics of the variable and object of observation as well as the relative position between the object of observation and the variable can be analyzed [8][10]. Biplot analysis aims to describe the rows (objects) and columns (variables) that exist in the data matrix together in a low-dimensional graph (usually two or three) [14][15][16]. This description includes the diversity and correlation between variables, as well as the proximity between objects which will later be able to identify the grouping of objects. Biplot analysis is able to directly display the defining variable or the most dominant variable from a group of objects formed in the results of the biplot analysis display [17].

\subsection{Path Analysis}

Path analysis is a development of regression analysis, involving more than one function [18]. The model in path analysis is a system of equations formed based on a path diagram. Solving the system of equations needs to be done simultaneously (simultaneously), starting from parameter estimation, hypothesis testing, to interpretation. One of the important components in path analysis is the path diagram. Path diagrams are used to describe causality between variables [7]. With the path diagram, it can be seen the direct and indirect effects of each variable. The cause and effect relationship on the path diagram is shown in the direction of the arrows. There are two arrow notations, namely a one-way arrow which states the direct effect of exogenous variables on endogenous variables, and two-way arrows that show the correlation between exogenous variables [8]. Here is an example of a simple path diagram:

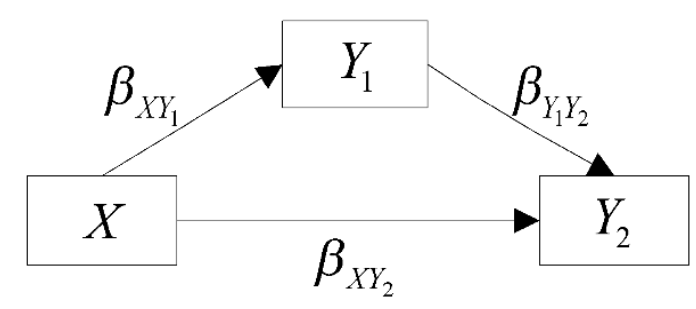

Fig. 1: Simple Linear Path Diagram

Path analysis is based on the assumption of linearity so that it can only be applied to linear problems characterized by the curve of the relationship between exogenous variables and endogenous variables being straight. When the linearity assumption cannot be met, an alternative way is developed to overcome the problem, namely the non-linear path model. Non-linear path analysis is a method to obtain a non-linear model that states the relationship between exogenous variables and endogenous variables, whose pattern does not follow a straight line, but follows a certain curved shape, such as quadratic, cubic, polynomial degree $\mathrm{k}, \operatorname{logarithm}$, exponential, and others [19].

In nonlinear regression, the regression model is assumed that the pattern of the relationship between the response variable and the predictor variable can be described in a certain function. 
Here is the shape of the quadratic curve:

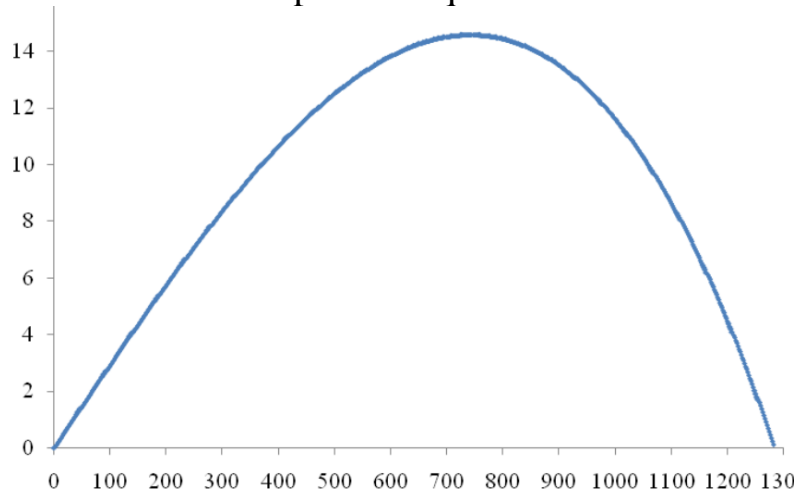

Fig. 2: Quadratic Curve

A simple nonlinear path model with polynomial degree $\mathrm{k}=2$ is described as follows:

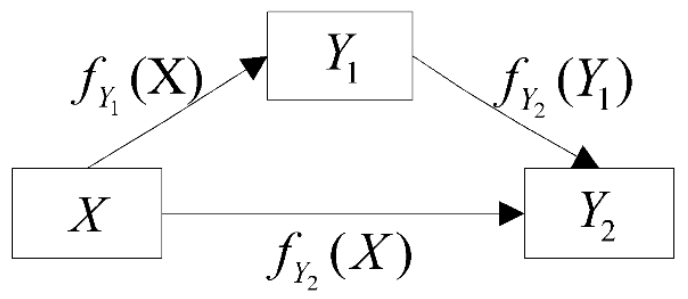

Fig. 3: Simple Nonlinear Path Diagram

\section{Methods}

This research is mix-method research that combines quantitative and qualitative research. Straus and Corbin [9] argue that a qualitative approach is a research approach that can be used to reveal and understand something behind a phenomenon that is not at all known or is also used to gain insight into something that has just been discovered. In the qualitative method, this study applies a qualitative Discourse Network Analysis (DNA) approach. Sources of DNA data come from various information in cyberspace (mass media, journals, articles, etc.) that are in accordance with the research context. DNA is a qualitative analysis used to identify variables related to Food Security in Indonesia Post-Covid-19 Pandemic.

Based on the search results in cyberspace, obtained about 60 relevant content discussing the reconstruction of non-linear path analysis accompanied by measurement models on food security models in Indonesia after the Covid-19 pandemic based on big data related to this research. The content is then used for DNA analysis by processing it on the Discourse Network Analyzer software. In DNA data processing, statements, actors, concepts/issues, sentiments, along with the origin of the organization. As for the quantitative method, this study uses descriptive statistical analysis, biplot, cluster, and non-linear path analysis (square and cubic).

\section{Results and Discussion}

\subsection{Data Scrapping and DNA Analysis}

Based on the results of the Discourse Network Analysis (DNA), two things were obtained, namely issues and actors in organizations related to food security in Indonesia after the Covid-19 pandemic. The results of DNA analysis on content obtained from cyberspace are presented in Figure 4 below.

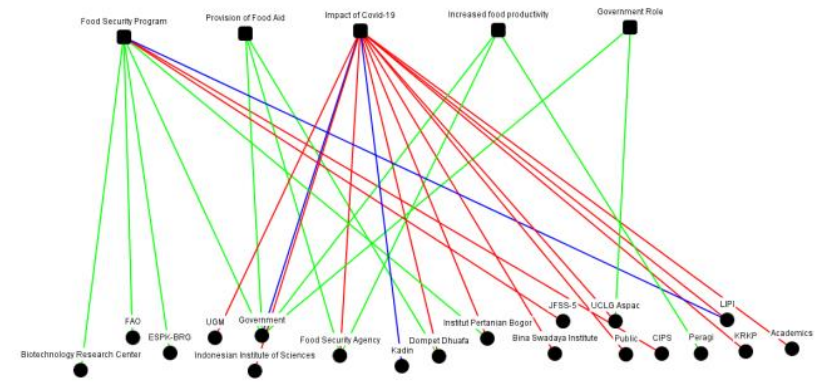

Fig. 4: Main Issues of Food Security in Indonesia Post-Covid-19 Pandemic

Source: Researcher Process, 2021

In Figure 4 there is also a black circle icon that shows actors in organizations on food security in Indonesia after the Covid-19 pandemic and a black square icon that shows the issues in the topic. The green line shows the narrative of positive sentiment, the red line shows negative sentiment, while the blue line shows some discourses that contain positive and negative sentiment results. The results of DNA analysis show that there are 43 actors from 4 organizations who have different opinions regarding food security in Indonesia after the Covid19 pandemic are classified into five main concepts or issues. The mapping image above can provide information that there are several actors who speak or express their opinions to the public regarding the five main issues of food security in Indonesia after the Covid-19 pandemic.

Based on the search for topics regarding food security in Indonesia after the Covid-19 pandemic, according to this study, several issues/concepts were 
obtained that could be explored further as consideration for displaying complete data. Thus, the 60 issues are then grouped into 5 main issues (issue groups).

Based on the search for topics in cyberspace regarding food security in Indonesia after the Covid19 pandemic, several stakeholders were found who were involved and gave their opinions about food security in Indonesia after the Covid-19 pandemic. The stakeholders are then grouped into several actor themes. In this regard, the following proposition can be formulated:

1) Government efforts in increasing food productivity can determine the increase in food productivity

2) The introduction of technology to farmers can determine the increase in food productivity

3) The development of modern agriculture can determine the increase in food productivity

4) The manufacture of new high yielding varieties can determine the increase in food productivity

5) The process of distributing rice food aid can determine the provision of food assistance

6) Helping the community not to experience food insecurity conditions can determine the provision of food assistance

7) The pandemic has an impact on people's food security can determine the impact of covid-19

8) Disrupting the handling of stunting nationally can determine the impact of covid-19

9) The lack of food availability can determine the impact of Covid-19

10) The pandemic has an impact on the safety of life can determine the impact of covid-19

11) Increasing the food security index can determine the impact of covid-19

12) The decrease in people's food consumption can determine the impact of covid-19

13) World food shortages and crises can determine the impact of covid-19

14) Community food insecurity can determine the impact of covid-19

15) Disruption of the food logistics system can determine the impact of COVID-19

16) The allocation of food security can determine the impact of covid-19

17) National food availability can determine the impact of covid-19

18) Uncertainty about food security can determine the impact of COVID-19

19) The instability of the economic sector can determine the impact of covid-19

20) The threat of a recession and a food crisis could determine the impact of covid-19
21) The decline in the order of people's lives can determine the impact of Covid-19

22) The decline in local economic development can determine the food security program

23) Food estate program can determine food security program

24) New methods in food security can define food security programs

25) Food trade policies can determine food security programs

26) Increased food production can determine food security programs

27) Challenges and food security can determine food security programs

28) Utilization of local food can determine food security programs

29) Biofloc system fish farming can determine food security programs

30) Increasing the supply of rice can determine the role of the government

31) Absorbing regional aspirations can determine the role of government

32) Maintaining price stability can determine the government's role

33) Expansion of land with food estate can determine the role of government

Of the 33 proportions above that affect the five main issues that can determine food security in Indonesia after the Covid-19 pandemic. Based on these minor propositions, issues can be divided into three parts (groups). First, the input issue consists of issues related to the opinions of actors discussing Food Productivity Improvement, Provision of Food Assistance, the Impact of Covid-19, Food Security Programs, and the Role of the Government. Second, the issue of the process consists of issues related to Government Efforts, Economic Stability, and the Impact of Covid-19. Third, the output issue which includes food security in Indonesia after the Covid19 pandemic referred to in this study is the measurement of the food security model in Indonesia after the Covid-19 pandemic. The interrelationships between the sections (groups) of these issues can be used to construct major propositions.

1) Input issues affect process issues

2) Process issues affect output issues

3) Output issues affect food security in Indonesia after the Covid-19 pandemic

According to [1] a theory or model can be presented through one or a combination of the following 3 forms: 
a) Verbal formulation. In this form, it means that the theory or model is presented in a series of descriptions which are theoretical statements.

b) Mathematical formula

c) Curves, graphs, or displays

With reference to this perspective, from the minor and major propositions that have been mentioned, the sub-models in carrying out the Reconstruction of Non-Linear Path Analysis with Measurement Models on the Food Security Model in Indonesia Post-Covid-19 Pandemic Based on Big Data based on the concept of issues can be arranged as follows.

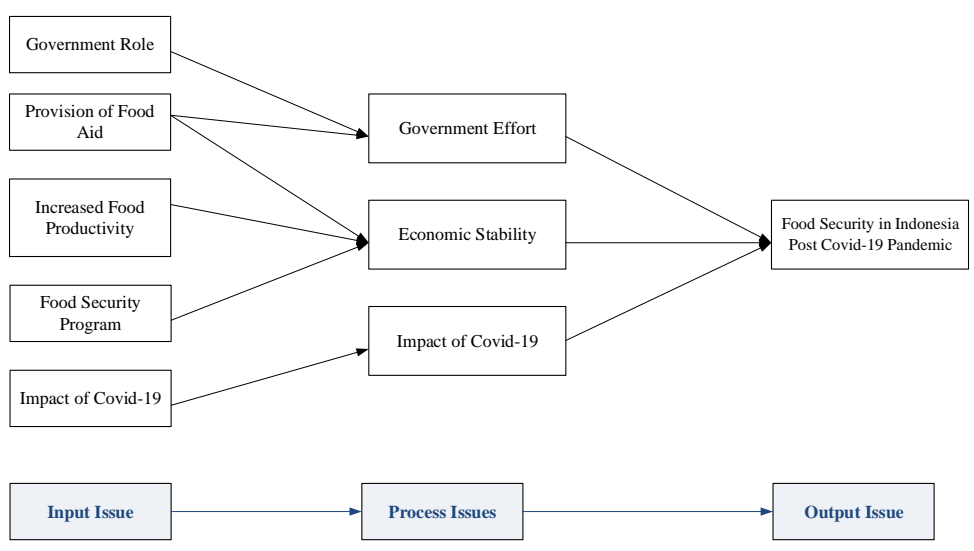

Fig. 5: Research Model Results of DNA Analysis

\subsection{Data Scrapping and DNA Analysis}

Descriptive statistics in this study are used to provide an overview of food security data. Food security has one mediating variable and three independent variables with the following details.

Table 1. Descriptive Statistics

\begin{tabular}{|l|c|c|c|c|c|}
\hline \multicolumn{1}{|c|}{ Score } & $\begin{array}{c}\text { Food } \\
\text { Productivity } \\
(\mathbf{X 1})\end{array}$ & $\begin{array}{c}\text { Provision of } \\
\text { Food Aid (X2) }\end{array}$ & $\begin{array}{c}\text { Impact } \\
\text { of } \\
\text { Covid- } \\
\mathbf{1 9}(\mathbf{X 3})\end{array}$ & $\begin{array}{c}\text { Economic } \\
\text { Stability } \\
(\mathbf{Y 1})\end{array}$ & $\begin{array}{c}\text { Food } \\
\text { Security } \\
\text { (Y2) }\end{array}$ \\
\hline Minimum & 2.83 & 1.90 & 2.67 & 2.67 & 2.23 \\
\hline $\begin{array}{l}\text { First } \\
\text { Quartile }\end{array}$ & 3.13 & 2.90 & 3.56 & 3.33 & 2.86 \\
\hline median & 3.41 & 3.10 & 3.78 & 3.67 & 3.28 \\
\hline Average & 3.39 & 3.16 & 3.79 & 3.68 & 3.26 \\
\hline $\begin{array}{l}\text { Third } \\
\text { Quartile }\end{array}$ & 3.57 & 3.47 & 4.00 & 4.00 & 3.59 \\
\hline Maximum & 4.26 & 4.27 & 4.67 & 5.00 & 4.21 \\
\hline
\end{tabular}

1) Food Productivity

Food Productivity which consists of dry grain weight harvested, type of plant, cropping pattern, cropping system, type of variety, and amount of fertilizer has an average of 3.39. This means that most respondents have a neutral opinion regarding Food Productivity. Respondents gave the smallest value of 2.83 which means neutral, while the highest value of 4.26 which means agree.

2) Provision of Food Aid

The provision of Food Aid which consists of the right target, the right quality and quantity, the right price, the right time, and the right administration has an average of 3.16. This means that most respondents have a neutral opinion regarding the provision of food assistance. Respondents gave the smallest value of 1.90 which means disagree, while the highest value of 4.27 which means agree.

3) Impact of Covid-19

The impact of Covid-19 consists of a decrease in income, the ability of the community to meet their daily needs, expenses, the economic life of the community, fulfillment of needs, efficiency in spending, rising raw material prices, and delays in the delivery of raw materials has an average of 3.79. This means that most respondents agree with the impact of Covid-19. Respondents gave the smallest value of 2.67 which means neutral, while the highest value of 4.67 which means strongly agree.

4) Economic Stability

Economic stability has an average of 3.68, which means that some respondents chose to answer agree related to economic stability. Respondents gave the smallest value of 2.67 which means neutral, while the highest value of 5.00 which means strongly agree.

5) Food security

Food Security which consists of staple food availability, stability of staple food availability, food access, and food utilization has an average of 3.26. This means that most respondents have a neutral opinion regarding food security. Respondents gave the smallest value of 2.23 which means neutral, while the highest value of 4.21 which means agree.

\subsection{Correlation between Variables}

Correlation between variables is used to see the close relationship between variables in the study. The correlation value is explained by the following matrix

Table 2. Correlation between variables

\begin{tabular}{|c|c|c|c|c|c|}
\hline & $\mathbf{X 1}$ & $\mathbf{X 2}$ & $\mathbf{X 3}$ & $\mathbf{Y 1}$ & Y2 \\
\hline $\mathbf{X 1}$ & 1.00 & 0.25 & -0.02 & 0.06 & 0.46 \\
\hline $\mathbf{X 2}$ & 0.25 & 1.00 & 0.05 & 0.32 & 0.69 \\
\hline $\mathbf{X 3}$ & -0.02 & 0.05 & 1.00 & -0.11 & 0.10 \\
\hline $\mathbf{Y 1}$ & 0.06 & 0.32 & -0.11 & 1.00 & 0.08 \\
\hline $\mathbf{Y 2}$ & 0.46 & 0.69 & 0.10 & 0.08 & 1.00 \\
\hline
\end{tabular}


Based on the correlation matrix, it can be concluded that:

1) Food Productivity (X1) has a close relationship with the Provision of Food Assistance (X2) of 0.25 with a direct (positive) relationship.

2) Food Productivity (X1) has a close relationship with the Covid-19 Impact (X3) of 0.02 with an inverse (negative) relationship.

3) Food Productivity (X1) has a close relationship with Economic Stability (Y1) of 0.06 with a direct (positive) relationship.

4) Food Productivity (X1) has a close relationship with Food Security (Y2) of 0.46 with a direct (positive) relationship.

5) The provision of Food Assistance (X2) has a close relationship with the Impact of Covid-19 (X3) of 0.05 with a direct (positive) direction of the relationship.

6) The provision of Food Aid (X2) has a close relationship with Economic Stability (Y1) of 0.32 with a direct (positive) relationship.

7) The provision of Food Assistance (X2) has a close relationship with Food Security (Y2) of 0.69 with a direct (positive) relationship.

8) The impact of Covid-19 (X3) has a close relationship with Economic Stability (Y1) of 0.11 with an inverse (negative) direction of the relationship.

9) The impact of Covid-19 (X3) has a close relationship with Food Security (Y2) of 0.09 with a direction that is directly proportional (positive).

10) Economic Stability (Y1) has a close relationship with Food Security (Y2) of 0.08 with a direct (positive) relationship.

\subsection{Cluster Analysis}

Before performing cluster validation, the data is standardized first because the units of each variable are different. The following is a plot for selecting the best number of clusters using the Silhouette Index.

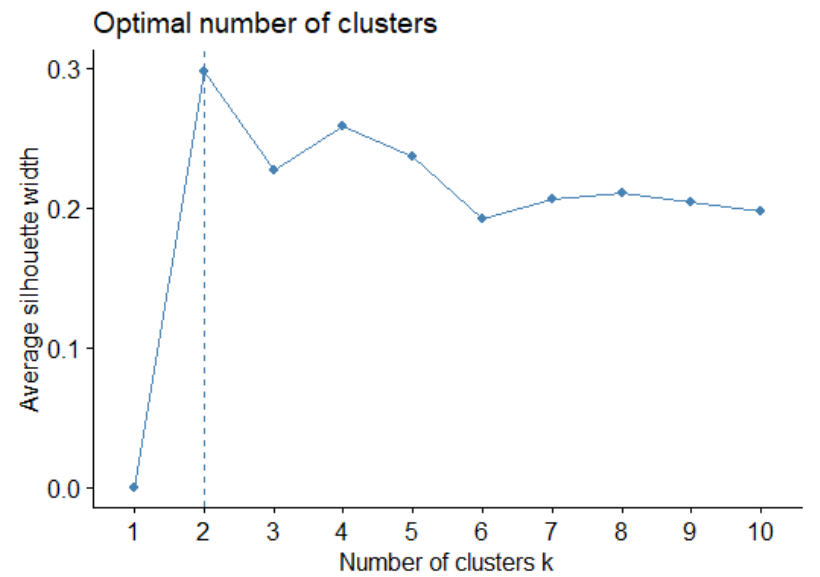

Fig. 6: Silhouette Index Results

Based on the graph above, cluster validation using the Silhouette Index is known that the optimal number of clusters in this study is two clusters. The Dendogram cluster is projected using R software as shown below. The dendogram is used to see the clusters that are formed.

\section{Cluster Dendrogram}

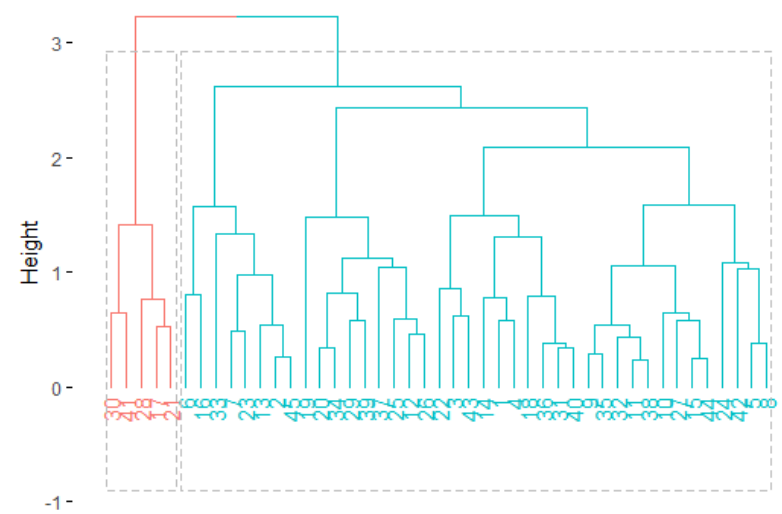

Fig. 7: Dendogram

From the dendogram with two clusters, the results obtained are clusters with significantly different groupings, as evidenced by the absence of clusters that have the same height. The number of suitable clusters in this study is two clusters. It can be seen that the cluster that has the most members is the first cluster (blue in the graph).

The results of grouping food security based on food products, providing food assistance, the impact of Covid-19, and economic stability using cluster analysis with a complete algorithm with details in table 3 below:

Table 3. Cluster Analysis Results

\begin{tabular}{|c|c|c|}
\hline Cluster & Member & Total \\
\hline \multirow{4}{*}{1} & $1,2,3,4,5,6,7,8,9$, & \\
& $10,11,12,13,14,15$, & 40 \\
& $16,17,19,20,21,23$, & \\
& $24,25,26,27,28,30$, & \\
& $35,36,37,38,39,40$, & \\
\hline
\end{tabular}




\begin{tabular}{|c|c|c|}
\hline & $41,43,44,45$ & \\
\hline 2 & $18,22,29,31,42$ & 5 \\
\hline
\end{tabular}

Based on table 3, the cluster with the most members is cluster one which consists of forty respondents, while cluster two has five respondents.

Table 4. Average of Each Cluster

\begin{tabular}{|l|c|c|}
\hline \multicolumn{1}{|c|}{ Variable } & Cluster 1 & Cluster 2 \\
\hline Food Productivity (X1) & 3.41 & 3.80 \\
\hline $\begin{array}{l}\text { Provision of Food Aid } \\
(\mathrm{X} 2)\end{array}$ & 3.16 & 3.58 \\
\hline Impact of Covid-19 (X3) & 3.78 & 3.75 \\
\hline Economic Stability (Y1) & 3.68 & 3.75 \\
\hline Food Security (Y2) & 3.25 & 3.48 \\
\hline
\end{tabular}

1) Food Productivity

Food productivity which consists of dry grain weight harvested, type of crop, cropping pattern, cropping system, type of variety, and amount of fertilizer has an average of 3.41 in cluster one and 3.80 in cluster two. This means that most respondents in cluster one have a neutral opinion regarding Food Productivity, while most respondents in cluster two agree.

2) Provision of Food Aid

The provision of Food Aid which consists of the right target, the right quality and quantity, the right price, the right time, and the right administration has an average of 3.16 in cluster one and 3.58 in cluster two. This means that most respondents in cluster one have a neutral opinion regarding the provision of food assistance, while most respondents in cluster two agree.

3) Impact of Covid-19

The impact of Covid-19 consists of a decrease in income, the ability of the community to meet their daily needs, expenses, the economic life of the community, fulfillment of needs, efficiency in spending, rising raw material prices, and delays in the delivery of raw materials has an average of 3.78 in the cluster. one and 3.75 in cluster two. This means that the majority of respondents in both clusters agree regarding the impact of Covid-19.

4) Economic Stability

Economic stability has an average of 3.68 in cluster one and 3.75 in cluster two. This means that most respondents in both clusters agree with regard to economic stability.

5) Food security

Food Security which consists of staple food availability, stability of staple food availability, food access, and food utilization has an average of 3.25 in cluster one and 3.48 in cluster two. This means that most respondents in both clusters have a neutral opinion regarding Food Security.

\subsection{Biplot Analysis}

The following is a table of 5 Eigenvalues along with the percentage of diversity obtained using $R$ software

Table 5. Eigenvalues and Percentage of Diversity Biplot Analysis

\begin{tabular}{|c|c|c|c|}
\hline Component & $\begin{array}{c}\text { Eigenvalu } \\
\mathbf{e}\end{array}$ & $\begin{array}{c}\text { Variety } \\
\text { (Percent) }\end{array}$ & $\begin{array}{c}\text { Cumulative Variety } \\
\text { (Percent) }\end{array}$ \\
\hline 1 & 2.04 & 40.78 & 40.78 \\
\hline 2 & 1.12 & 22.33 & 63.11 \\
\hline 3 & 0.93 & 18.69 & 81.80 \\
\hline 4 & 0.68 & 13.55 & 95.35 \\
\hline 5 & 0.23 & 4.65 & 100.00 \\
\hline
\end{tabular}

The percentage of cumulative variance in table 5 shows that the biplot suitability value obtained is $63.11 \%$ so it can be concluded that the biplot analysis can represent objects more than half of the total diversity of the data. Because the percentage of the cumulative variance of the first and second components is quite high, the results of the biplot analysis are good enough to explain the data although the other $36.89 \%$ have not been explained. More than half of the total data has been represented. The percentage of variance from the first component to the second component experienced a sharp decrease in the percentage of variance, while the third and subsequent components tended to be more gentle. This shows that the addition of the second component has an effect on the diversity described. In accordance with the provisions of the biplot analysis that only the first and second components are selected to represent the biplot representation, the percentage of cumulative variance that can be explained by the two components is about $63.11 \%$. However, the biplot suitability value is still less than $70 \%$ so this analysis is still not representative enough to see food security. 


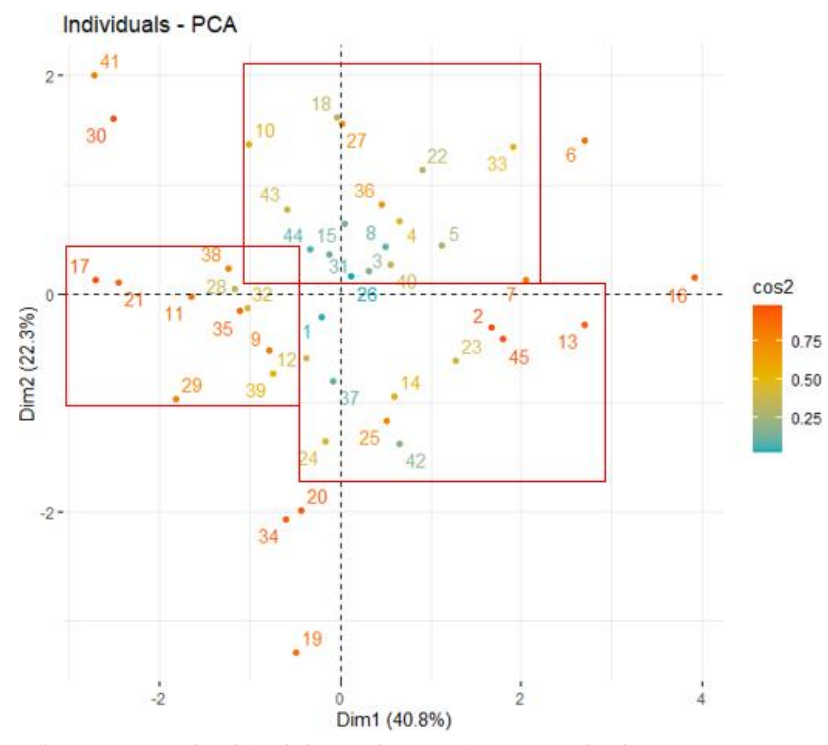

Fig. 8: Similarities in Characteristics Between Observation Objects

The similarity of characteristics between observation objects can be identified through the position of objects that are close to each other. Based on the biplot graph above, the respondents are grouped into several groups, including

Table 6. Grouping with Biplot Analysis

\begin{tabular}{|c|c|c|}
\hline Group & Member & Total \\
\hline 1 & $17,21,38,11,28,32,35,9,29,12,39$ & 10 \\
\hline 2 & $\begin{array}{c}10,18,43,22,33,36,44,15,31,8,4, \\
5,3,40,26,7\end{array}$ & 16 \\
\hline 3 & $\begin{array}{c}1,12,37,7,24,25,14,42,2,23,45, \\
13\end{array}$ & 12 \\
\hline
\end{tabular}

Based on the relative similarity of objects between the observations above, it can also be seen that the cosine value is used to find out information about objects that are well represented. The cosine value obtained from each object of observation can be represented by the following graph. This is a visualization of the cosine value.

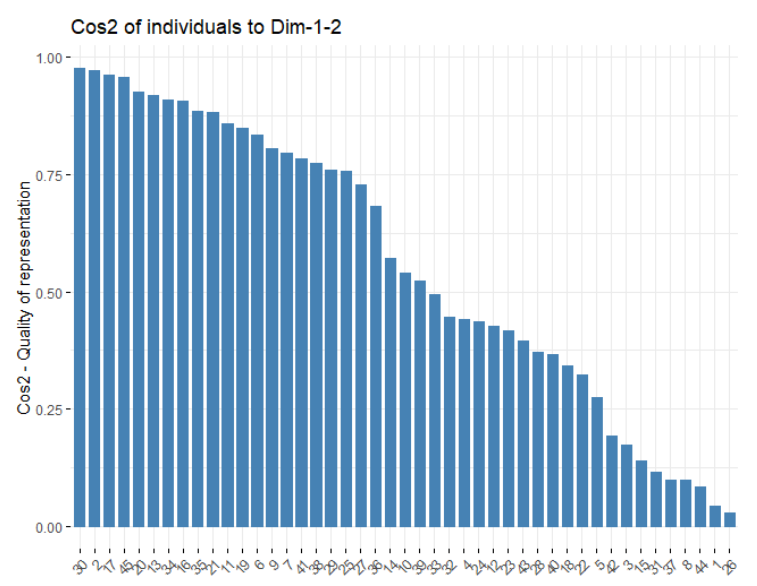

Fig. 9: Cosine Value for Each Object

Based on the picture above, there are nineteen respondents who are well represented. This is because the cosine value of the nineteenth has a cosine value of the region having a value of more than 0.7 .

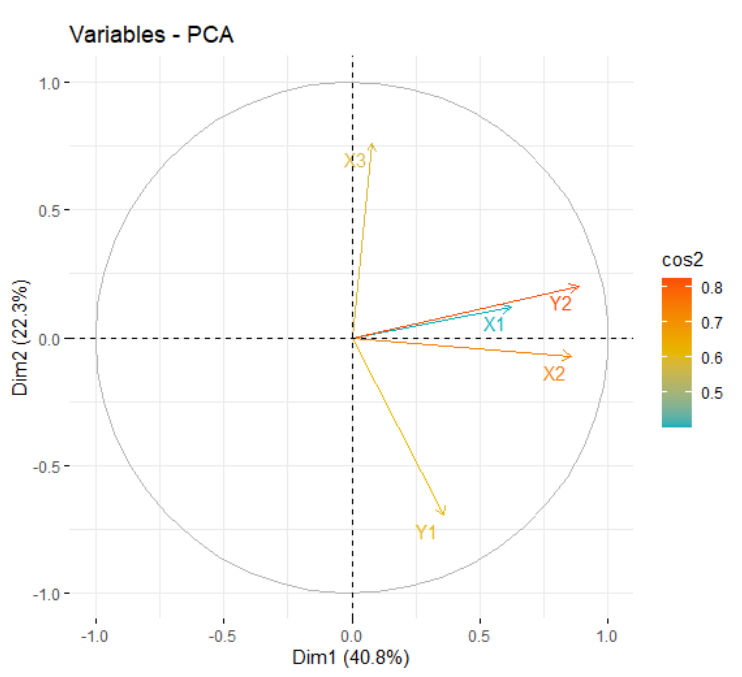

Fig. 10: Variable Diversity

Based on the figure, the variable with the greatest diversity is the food security variable (Y2), while Food Productivity (X1) has the smallest diversity. In addition, if the two vectors form an angle close to zero degrees, the variable has a positive correlation, while if it is opposite and forms a wide-angle, the variable is negatively correlated. If the two indicators form 90 degrees, the variables are not correlated. First, the variable X1 forms an acute angle or is positively correlated with several variables including $\mathrm{X} 2, \mathrm{X} 3, \mathrm{Y} 1$, and $\mathrm{Y} 2$. Second, the variable $\mathrm{X} 2$ has a positive correlation with the variables $\mathrm{Y} 1$, and $\mathrm{Y} 2$. Third, the $\mathrm{X} 3$ variable has a positive correlation with the $\mathrm{Y} 2$ variable and has a negative correlation with the $\mathrm{Y} 1$ variable. Fourth, the Y1 variable has a positive correlation with the $\mathrm{Y} 2$ variable.

The advantages of each group of objects of observation can be seen through the variable vector. Objects that are located in the direction of the variable vector, it can be said that the object has an advantage in the characteristics of the variable. Vice versa, if the object is located in the opposite direction to the direction of the variable vector, it can be said that the object does not have an advantage in the characteristics of the variable. 


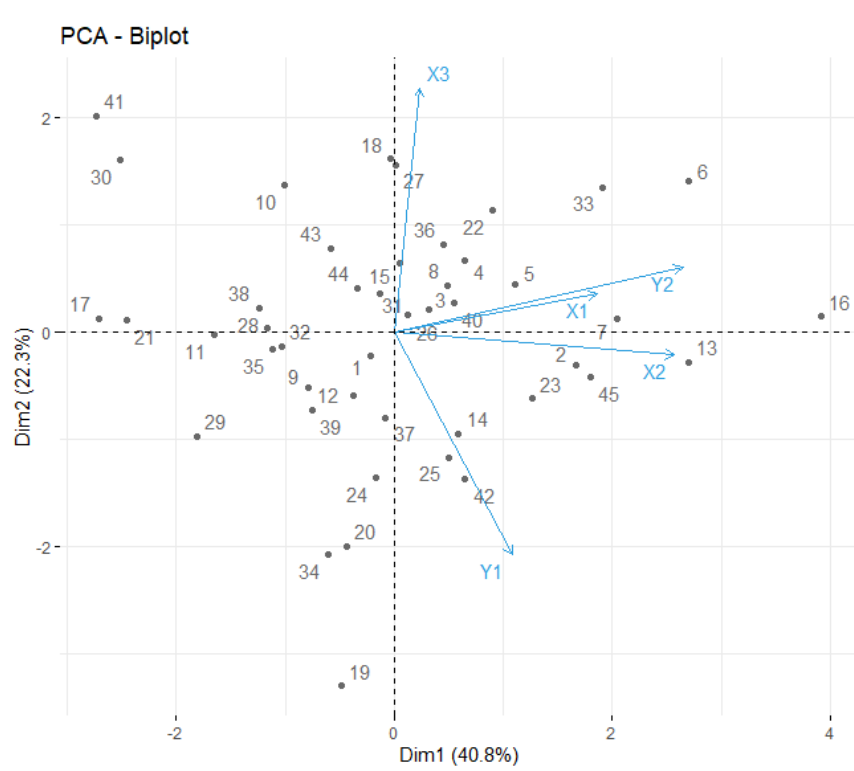

Fig. 11: Relation of Objects with Variables

Based on the picture above, the relationship between objects (in this case respondents) and variables can be observed with the following details.

Table 7. Relation of Objects and Variables

\begin{tabular}{|l|l|}
\hline \multicolumn{1}{|c|}{ Variable } & \multicolumn{1}{|c|}{ Nearby Object } \\
\hline Food Productivity (X1) & $31,26,3,40,5,7$ \\
\hline Provision of Food Aid (X2) & $23,2,45,13,7$ \\
\hline Impact of Covid-19 (X3) & $31,15,44,27,18$ \\
\hline Economic Stability (Y1) & $14,25,42,37$ \\
\hline Food Security (Y2) & $31,3,8,5$ \\
\hline
\end{tabular}

Based on figure 12 and table 7, it is found that Food Productivity (X1) has the closest proximity to the 3rd, 5th, 7th, 26th, 31st, and 40th objects. Provision of Food Aid (X2) has the closest proximity to the object. 2nd, 7th, 13th, 23rd, and 45th. Impact of Covid-19 (X3) has the closest proximity to objects 15 th, 18 th, 27 th, 31 st, and 44th. Economic Stability (Y1) has the closest proximity to the 14th, 25th, 37th, and 42nd objects. Food Security (Y2) has the closest proximity to the 3rd, 5th, 8th, and 31st objects.

\subsection{Quadratic Path Analysis Results}

\subsubsection{Linearity Test}

Table 8. X1-Y1 relationship

\begin{tabular}{|c|c|c|c|c|}
\hline & R-squared 1 & R-squared 2 & F & p-value \\
\hline linear & 0.03 & 0.05 & 0.62 & 0.54 \\
\hline Quadratic & 0.00 & 0.00 & 0.21 & 0.89 \\
\hline Cubic & 0.00 & 0.00 & 0.17 & 0.95 \\
\hline
\end{tabular}

Based on table $8, \mathrm{p}$-value on the quadratic is 0.887 more than 0.05 so that the quadratic assumption is fulfilled on $\mathrm{X} 1$ against $\mathrm{Y} 1$

Table 9. X2-Y1 relationship

\begin{tabular}{|c|c|c|c|c|}
\hline & R-squared 1 & R-squared 2 & F & p-value \\
\hline linear & 0.11 & 0.11 & 0.15 & 0.86 \\
\hline Quadratic & 0.00 & 0.00 & 0.02 & 0.99 \\
\hline Cubic & 0.00 & 0.00 & 0.00 & 1.00 \\
\hline
\end{tabular}

Based on table 9, p-value on the quadratic is 0.977 more than 0.05 so that the quadratic assumption is met at $\mathrm{X} 2$ to $\mathrm{Y} 1$

Table 10. X3-Y1 Relationship

\begin{tabular}{|c|c|c|c|c|}
\hline & R-squared 1 & R-squared 2 & F & p-value \\
\hline linear & 0.03 & 0.11 & 0.00 & 0.99 \\
\hline Quadratic & 0.00 & 0.00 & 0.26 & 0.85 \\
\hline Cubic & 0.00 & 0.00 & 0.86 & 0.49 \\
\hline
\end{tabular}

Based on table $10, \mathrm{p}$-value on the quadratic is 0.85 more than 0.05 so that the quadratic assumption is fulfilled at $\mathrm{X} 3$ to $\mathrm{Y} 1$

Table 11. X1-Y2 relationship

\begin{tabular}{|c|c|c|c|c|}
\hline & R-squared 1 & R-squared 2 & F & p-value \\
\hline linear & 0.23 & 0.24 & 0.62 & 0.54 \\
\hline Quadratic & 0.00 & 0.00 & 0.00 & 1.00 \\
\hline Cubic & 0.00 & 0.00 & 0.10 & 0.98 \\
\hline
\end{tabular}

Based on table 11, p-value on the quadratic of 1 is more than 0.05 so that the quadratic assumption is fulfilled on X1 against Y2

Table 12. X2-Y2 relationship

\begin{tabular}{|c|c|c|c|c|}
\hline & R-squared 1 & R-squared 2 & F & p-value \\
\hline linear & 0.52 & 0.52 & 0.62 & 0.54 \\
\hline Quadratic & 0.00 & 0.00 & 0.51 & 0.68 \\
\hline Cubic & 0.00 & 0.00 & 0.00 & 1.00 \\
\hline
\end{tabular}

Based on table 12 , p-value on the quadratic is 0.68 more than 0.05 so that the quadratic assumption is met at $\mathrm{X} 2$ to $\mathrm{Y} 2$

Table 13. X3-Y2 Relationship

\begin{tabular}{|c|c|c|c|c|}
\hline & R-squared 1 & R-squared 2 & F & p-value \\
\hline linear & 0.08 & 0.08 & 0.36 & 0.70 \\
\hline Quadratic & 0.00 & 0.00 & 1.06 & 0.37 \\
\hline Cubic & 0.00 & 0.00 & 0.02 & 0.99 \\
\hline
\end{tabular}

Based on table 13 , p-value on the quadratic is 0.37 more than 0.05 so that the quadratic assumption is met at $\mathrm{X} 3$ to $\mathrm{Y} 2$

Table 14. Y1-Y2 Relationship

\begin{tabular}{|c|c|c|c|c|}
\hline & R-squared 1 & R-squared 2 & F & p-value \\
\hline linear & 0.04 & 0.09 & 0.42 & 0.66 \\
\hline Quadratic & 0.00 & 0.00 & 0.69 & 0.56 \\
\hline Cubic & 0.00 & 0.00 & 0.54 & 0.70 \\
\hline
\end{tabular}


Based on table 14, p-value at the quadratic is 0.56 more than 0.05 so that the quadratic assumption is met at $\mathrm{Y} 1$ to $\mathrm{Y} 2$

\subsubsection{Quadratic Path Direct Model}

The direct model of quadratic path analysis obtained from this study, namely:

$$
Y_{1}=-0.12-0.08 X_{1}+0.12 X_{1}^{2}+0.31 X_{2}-0.14 X_{3}
$$

Directly, every increase in the value of Food Productivity (X1) by 1 unit and other variables are considered constant, will reduce the value of Economic Stability (Y1) by 0.08 . Every increase in the value of Food Productivity (X1) in a quadratic by 1 unit and other variables are considered constant, will increase the value of Economic Stability (Y1) by 0.12 . Each increase in the value of Food Assistance (X2) by 1 unit and other variables are considered constant, will increase the value of Economic Stability (Y1) by 0.31 . Every increase in the value of the Covid-19 Impact (X3) by 1 unit and other variables are considered constant, will reduce the value of Economic Stability (Y1) by 0.14.

\subsubsection{Quadratic Path Indirect Model}

The direct model of quadratic path analysis obtained from this study, namely:

$$
Y_{2}=-0.05-0.15 Y_{1}+0.28 X_{1}+0.05 X_{1}^{2}+0.65 X_{2}+0.04 X_{3}
$$

Indirectly, every increase in the value of Economic Stability (Y1) by 1 unit and other variables are considered constant, will reduce the value of Food Security (Y2) by 0.15. Every increase in the value of Food Productivity (X1) by 1 unit and other variables are considered constant, will increase the value of Food Security (Y2) by 0.28. Each increase in the value of Food Productivity (X1) is 1 unit quadratic and other variables are considered constant, it will increase the value of Food Security (Y2) by 0.05 . Each increase in the value of Food Assistance (X2) by 1 unit and other variables are considered constant, will increase the value of Food Security (Y2) by 0.65 .

\subsubsection{Coefficient of Determination Total Quadratic Path \\ The coefficient of determination is 0.88 which means that the influence given by the independent variable simultaneously on the $\mathrm{Y}$ variable is 0.88 which is very strong.}

\subsection{Cubic Path Analysis Results}

\subsubsection{Live Model Cubic Path}

The direct model of cubic path analysis obtained from this study, namely:

$$
Y_{1}=-0.03-0.19 X_{1}+0.07 X_{1}^{3}+0.31 X_{2}-0.14 X_{3}
$$

Directly, every increase in the value of Food Productivity (X1) by 1 unit and other variables are considered constant, will reduce the value of Economic Stability (Y1) by 0.19 . Every increase in the value of Food Productivity (X1) by 1 unit cubic and other variables are considered constant, will increase the value of Economic Stability (Y1) by 0.07. Each increase in the value of the Provision of Food Aid (X2) by 1 unit and other variables are considered constant, will increase the value of Economic Stability (Y1) by 0.31 . Every increase in the value of the Covid-19 Impact (X3) by 1 unit and other variables are considered constant, it will reduce the value of Economic Stability (Y1) by 0.14 .

\subsubsection{Indirect Model Cubic Path}

The indirect model of cubic path analysis obtained from this study, namely:

$$
Y_{2}=-0.01-0.15 Y_{1}+0.26 X_{1}++0.02 X_{1}^{3}+0.66 X_{2}+0.05 X_{3}
$$

Indirectly, every increase in the value of Economic Stability (Y1) by 1 unit and other variables are considered constant, will decrease the value of Food Security (Y2) by 0.15 . Each increase in the value of Food Productivity (X1) by 1 unit and other variables are considered constant, will increase the value of Food Security (Y2) by 0.26. Each increase in the value of Food Productivity (X1) in cubic of 1 unit and other variables are considered constant, will increase the value of Food Security (Y2) by 0.02 . Each increase in the value of Food Assistance (X2) by 1 unit and other variables are considered constant, will increase the value of Food Security (Y2) by 0.66. Each increase in the value of the Covid-19 Impact (X3) by 1 unit and other variables are considered constant, will increase the value of Food Security (Y2) by 0.05 . Every increase in the value of the Covid-19 Impact (X3) by 1 unit and other variables are considered constant, it will reduce the value of Food Security (Y2) by 0.14 .

\subsubsection{Coefficient of Determination Total Cubic Path}

The coefficient of determination is 0.88 which means that the influence given by the independent variable simultaneously on the $\mathrm{Y}$ variable is 0.88 which is very strong.

\section{Conclusions and Suggestions}


The DNA results show that of the 33 proportions that affect the five main issues that can determine food security in Indonesia after the Covid-19 pandemic. Based on these minor propositions, issues can be divided into three parts (groups). First, the input issue consists of issues related to the opinions of actors discussing Food Productivity Improvement, Provision of Food Assistance, the Impact of Covid-19, Food Security Programs, and the Role of the Government. Second, the issue of the process consists of issues related to Government Efforts, Economic Stability, and the Impact of Covid-19. Third, the output issue which includes food security in Indonesia after the Covid-19 pandemic referred to in this study is the measurement of the food security model in Indonesia after the Covid-19 pandemic. The interrelationships between the sections (groups) of these issues can be used to construct major propositions. Based on cluster analysis, two clusters were obtained with cluster 1 consisting of 40 objects and cluster 2 consisting of 5 research objects.

The coefficient of determination for both quadratic and cubic path analysis is 0.88 , which means that the influence of the independent variable simultaneously on the $\mathrm{Y}$ variable is 0.88 , which is very strong. Thus, the model formed is quite good because the predictor variable is able to explain food security by $88 \%$ while the rest is explained by other factors outside the model.

The results of this study can be used by the Indonesian government is paying attention to food security in Indonesia during the Covid-19 pandemic. In order to improve food security in Indonesia, the government should pay more attention to food Productivity, Provision of Food Aid, Impact of Covid-19, and Provision of Food Aid. Based on the model formed, the factor that most influences food security in Indonesia is the provision of food assistance. Therefore, the government should pay more attention to the provision of food assistance. Especially the provision of assistance in areas that are difficult to reach, such as remote areas and slum settlements. The government also needs to improve the data collection system for the underprivileged so that the provision of assistance will be more optimal and on target.

The results of this study are as an instrument to overcome various problems of implementing food security policies in post-covid-19 Indonesia based on the practical implications of the research that has been carried out, namely encouraging the implementation of food security in Indonesia postcovid-19 in a measurable manner, encouraging actors to implement food security in Indonesia. post- covid-19 to maximize coaching programs by scheduling meetings with certain themes to improve skills and competencies in terms of food security, and encouraging the Government to act as a leading sector inviting the community, namely by intensively initiating forums such as the Forum Group Discussion to accommodate and accommodate the aspirations of various stakeholders.

\section{References:}

[1] Saediman, H., Gafaruddin, A., Hidrawati, Salam, I., Ulimaz, A., Rianse, I. S., Sarinah, and Taridala, S. A. A. (2021). The Contribution of Home Food Gardening Program to Household Food Security in Indonesia: A Review, WSEAS Transactions on Environment and Development, vol. 17, pp. 795-809.

[2] Almas, L. K., and Usman, M. (2021). Determinants of Wheat Consumption, Irrigated Agriculture, and Food Security Challenges in Egypt, WSEAS Transactions on Environment and Development, vol. 17, pp. 696-712.

[3] Ly, T. D., Dong, P. X., Anh, L. H., and An, P. T. H. (2020). The Effect of International Trade on Food Security at Southeast Asian Countries, WSEAS Transactions on Environment and Development, 16, 180-188.

[4] Trojanowski, T. (2021). SWOT Analysis of Sustainable Marketing Mix of Food Industry Enterprises, WSEAS Transactions on Environment and Development, 17, 997-1003.

[5] Osabohien, R., Olurinola, I. O., Matthew, O. A., and Igharo, A. E. (2021) Enabling Environment and Agriculture in ECOWAS: Implications for Food Security, WSEAS Transactions on Environment and Development, 17, 38-46.

[6] Paramita, E. L., \& Ihalauw, J. J. (2010). Anak Sebagai Future Market: Studl Autobiographical Memory. Journal of Management and Business, 9(1).

[7] Hair Jr, J. F., Babin, B. J., \& Anderson, R. E. (2010). A GLOBAL P-ERSPECTIVIE. Kennesaw: Kennesaw State University.

[8] Matijik, AA, \& Sumertajaya, IM (2011). Multiple Variable Print. Bogor: IPB Press.

[9] Widowati, W., \& Muzdalifah, L. (2017). Comparison of Classical Biplot Analysis and Robust Biplot on Mapping Private Universities in East Java. Journal of Research and Applications of Mathematics (JRAM), 1(1), 27-39. 
[10] Sartono, B., Affendi, FM, Syafitri, UD, Sumertajaya, IM, \& Anggraeni, Y. (2003). Multiple variable analysis. Bogor: IPB Press.

[11] Ariawan, R. (2013). Application of Visual Thinking Learning Approach Accompanied by Quick On The Draw Activities to Improve Students' Problem Solving and Mathematical Communication Skills (Doctoral dissertation, Universitas Pendidikan Indonesia).

[12] Dillon, WR Goldstein. M. (1984): Multivariate analysis: methods and applications. New York: John Wiley \& Sons.

[13] Li, CC (1975). Path Analysis-a primary. The Boxwood Press.

[14] Strauss, A., and Corbin, J. (1990). Basics of Qualitative Research: Grounded Theory Procedures and Techniques. SAGE Publications Inc.

[15] Sumardi, S., \& Fernandes, A. A. R. (2020). The influence of quality management on organization performance: service quality and product characteristics as a medium. Property Management.

[16] Yusuf, M., Fernandes, A. A. R., Kurniawan, S., \& Arisoesilaningsih, E. (2020, June). Initial soil properties of the restored degraded area under different vegetation cover in UB Forest, East Java, Indonesia. In Journal of Physics: Conference Series (Vol. 1563, No. 1, p. 012006). IOP Publishing.

[17] Arisoesilaningsih, E., Indriani, S., \& Fernandes, A. A. R. (2020, June). Community structure of fruit tree species on successful marginal land conservation in Jombang Regency, East Java Province, Indonesia. In Journal of Physics: Conference Series (Vol. 1563, No. 1, p. 012025). IOP Publishing.

[18] Fernandes, A. A. R., \& Cahyoningtyas, R. A. (2021, May). Structural equation modelling on Latent Variables to identify farmers satisfaction in East Java using Mixed-Scale Data. In Journal of Physics: Conference Series (Vol. 1872, No. 1, p. 012022). IOP Publishing.

[19] Fernandes, A. A. R., Solimun, F. U., Aryandani, A., Chairunissa, A., Alifa, A., Krisnawati, E., ... \& Rasyidah, F. L. N. (2021). Comparison Of Cluster Validity Index Using Integrated Cluster Analysis With Structural Equation Modelingthe War-PLS Approach. Journal of Theoretical and Applied Information Technology, 99(18).

\section{Creative Commons Attribution \\ License 4.0 (Attribution 4.0 International, CC BY 4.0)}

This article is published under the terms of the Creative Commons Attribution License 4.0 https://creativecommons.org/licenses/by/4.0/deed.en _US 